University of Nebraska - Lincoln

DigitalCommons@University of Nebraska - Lincoln

USDA National Wildlife Research Center - Staff Publications
U.S. Department of Agriculture: Animal and Plant Health Inspection Service

2009

\title{
Comparison of Injuries to Coyote From 3 Types of Cable Foot- Restraints
}

\author{
Patrick Darrow \\ USDA-APHIS-Wildlife Services
}

Ramona Skirpstunas

Utah State University, Logan, Department of Animal, Dairy, and Veterinary Sciences

S. Wade Carlson

USDA-APHIS-Wildlife Services

John Shivik

USDA-APHIS-Wildlife Services

Follow this and additional works at: https://digitalcommons.unl.edu/icwdm_usdanwrc

Part of the Environmental Sciences Commons

Darrow, Patrick; Skirpstunas, Ramona; Carlson, S. Wade; and Shivik, John, "Comparison of Injuries to Coyote From 3 Types of Cable Foot-Restraints" (2009). USDA National Wildlife Research Center - Staff Publications. 875.

https://digitalcommons.unl.edu/icwdm_usdanwrc/875

This Article is brought to you for free and open access by the U.S. Department of Agriculture: Animal and Plant Health Inspection Service at DigitalCommons@University of Nebraska - Lincoln. It has been accepted for inclusion in USDA National Wildlife Research Center - Staff Publications by an authorized administrator of DigitalCommons@University of Nebraska - Lincoln. 


\title{
Comparison of Injuries to Coyote From 3 Types of Cable Foot-Restraints
}

\author{
PATRICK A. DARROW, ${ }^{1}$ United States Department of Agriculture, Wildlife Services, National Wildlife Research Center, Utah State University, \\ Predator Ecology, BNR Room 163, Logan, UT 84322-5295, USA \\ RAMONA T. SKIRPSTUNAS, Department of Animal, Dairy, and Veterinary Sciences, Utah State University, 5700 Old Main Hill, Logan, UT 84322- \\ 5700, USA \\ S. WADE CARLSON, United States Department of Agriculture, Wildlife Services, 5151 Pentecost Drive Suite No. H, Modesto, CA 95356, USA \\ JOHN A. SHIVIK, United States Department of Agriculture, Wildlife Services, National Wildlife Research Center, Department of Wildland Resources, \\ Utah State University, Predator Ecology, BNR Room 163, Logan, UT 84322-5295, USA
}

\begin{abstract}
We compared injury rates among captured coyotes (Canis latrans) to determine if modifications to cable foot-restraints would decrease resulting injuries. Mean International Standardization Organization's injury scores of coyotes caught in 3 types of cable foot-restraints were 22.2, 37.9, and $60.4\left(F_{2,41}=4.63, P=0.015\right)$ for a chain-loop, standard cable, and sleeved cable, respectively. These results may be important for trappers and researchers to consider when using a cable foot-restraint device to capture wildlife. (JOURNAL OF WILDLIFE MANAGEMENT 73(8):1441-1444; 2009)
\end{abstract}

DOI: $10.2193 / 2008-566$

KEY WORDS cable foot-restraint, Canis latrans, capture device, coyote, foot snare, injury score.

Wildlife managers often use a variety of tools to capture animals when implementing management actions such as radiocollaring animals, obtaining wildlife population estimates, or responding to wildlife damage. One capture tool, the leg-hold trap, has been used since at least the 16th century (Bateman 1971). However, public attitudes in the United States and around the world towards leg-hold traps have become increasingly negative (Reiter et al. 1999, Harris et al. 2006). Negative public perception of the use of leghold traps has led to their ban in several United States states through ballot initiatives (Cockrell 1999, Orthmeyer et al. 2007), and such bans have impacted the ability of wildlife professionals to capture animals and resolve wildlife damage management issues.

In some states, such as California, the United States Department of Agriculture's Wildlife Services (USDA WS) program uses an integrated pest-management approach to assist livestock producers experiencing coyote (Canis latrans) damage (USDA WS 2006). Due to prohibitions on the use of leg-hold traps, WS specialists often use cable footrestraint devices to capture coyotes for many reasons, including the protection of micro-irrigation systems in fruit orchards and livestock protection. Public acceptance of the use of cable foot-restraints is slightly greater than for leghold traps (Reiter et al. 1999).

Research to improve capture devices continues and the knowledge base is growing. Shivik et al. (2000) compared efficiency, selectivity, and injury scores of coyotes caught in a variety of cable restraint devices. Other studies have compared efficiency, selectivity, and injuries caused by leghold traps, cage-traps, and cable restraint devices for capturing coyotes (Shivik et al. 2005) and red fox (Vulpes vulpes; Novak 1981, Muñoz-Igualada et al. 2008). Injuries caused to coyotes by various types of leg-hold traps have

${ }^{1}$ E-mail: patrick.a.darrow@aphis.usda.gov been examined in several studies (Olsen et al. 1986, Linhart et al. 1988, Onderka et al. 1990, Phillips et al. 1996), all of which indicated that padded jawed traps caused fewer severe injuries than unpadded traps.

With public pressure to improve capture device functions (increased selectivity and reduced injury), modifications to capture methods are also continuing. Several modifications, such as different restraint loop materials, are available or have been proposed, but no studies have compared injury scores of coyotes caught in modified cable foot-restraint devices. Our objective was to determine if modifications to cable foot-restraints would decrease injuries to coyotes caught in the devices.

\section{STUDY AREA}

We conducted testing in San Joaquin, Mariposa, Tuolumne, and Stanislaus counties, California, USA. We conducted all testing of the cable restraint devices outside of known San Joaquin kit fox (Vulpes macrotis mutica) range. Elevation ranged from below sea level in San Joaquin County to nearly $900 \mathrm{~m}$ in Mariposa County. The climate was characterized by cool, wet winters and warm, dry summers. Mean annual rainfall over the study area ranged from $32 \mathrm{~cm}$ to $86 \mathrm{~cm}$ in Stanislaus and Tuolumne counties, respectively. Mean annual snowfall varied from no snow in Stanislaus and San Joaquin counties to an average of $109 \mathrm{~cm}$ in Mariposa County. Mean high temperatures in July were $33^{\circ} \mathrm{C}$, with a mean low temperature in January of $0.6^{\circ} \mathrm{C}$. Topography varied from flat farm lands to semi-mountainous.

\section{METHODS}

Wildlife Services specialists used 3 variations of cable footrestraints to capture coyotes during their regular duties. Our analyses followed approval by the National Wildlife Research Center's Quality Assurance Unit (QA-1603). Our study began in May 2004 and ended in July 2006. 
We selected 5 WS specialists to test cable foot-restraints who had expressed interest in testing the 3 types of cable restraints, and provided wildlife management assistance for ranches that had historical or current damage caused by coyotes. WS specialists captured coyotes from January to September; however, the majority of snaring was conducted during June and July. We used an AST2 cable restraint thrower, previously known as the Wildlife Services Turman snare as described in Shivik et al. (2005), to place the cable on coyotes' legs. We set the thrower with a pan-tension of $2.04 \mathrm{~kg}$. When an animal stepped on the device's pan, a throw arm powered by 2 coil springs raised the cable loop up around the animal's leg and then cinched the restraint tight. Specialists securely staked all restraints to the ground and rounded the corners of all restraining locks with a metal file to remove sharp edges.

We tested 3 restraint types. We made the first cable restraint (standard) with $53.34 \mathrm{~cm}$ of 0.32 -cm-diameter $7 \times$ 19-strand cable with a cam-lock (Fig. 1A). We used a camlock with a sheer pin designed to break away the restraint when $>113 \mathrm{~kg}$ of pressure was applied to the restraint. For the second model (sleeved), we used an identical cable as the first model, but also incorporated a 4.45-cm-long, 0.476$\mathrm{cm}$-diameter clear plastic tube (surgical tubing) fitted over the cable at the end of the restraining loop (Fig. 1B). When the sleeved model tightened around the leg of the coyote, the cable surface in contact with the leg was encased in plastic tubing. For the third model (chain), instead of using only cable, we also incorporated $3.02 \mathrm{~cm}$ of $0.2-\mathrm{cm}^{-}$ diameter, twist-link chain that attached the lock to the end of the cable (Fig. 1C). When the chain model tightened around the leg of a coyote, the restraint loop consisted of both cable and chain. We equipped all snares with a swivel at the end of the cable where it was staked to the ground.

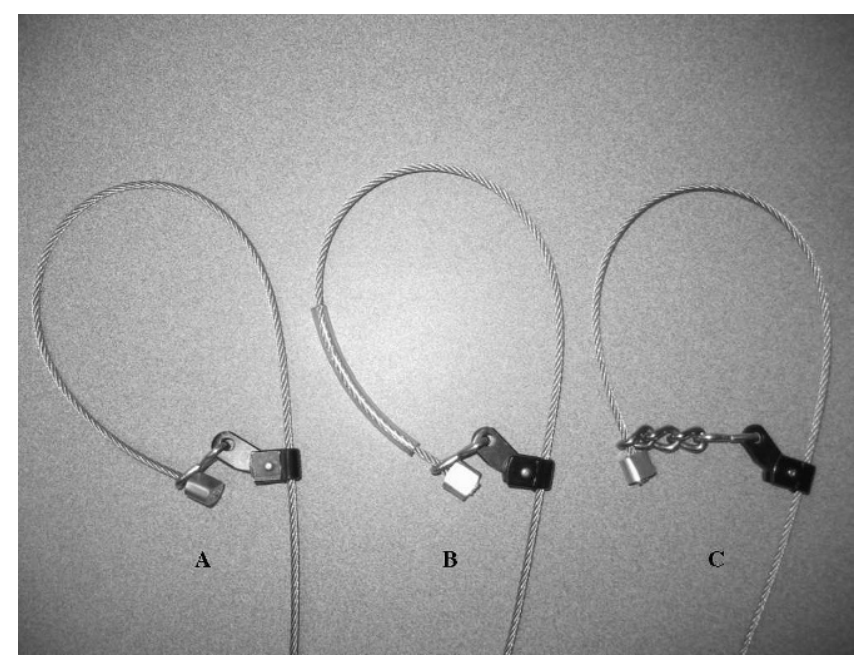

Figure 1. Cable foot-restraints used in a comparative study to examine injuries of coyotes caught in cable foot-restraint devices from May 2004 to July 2006 in central California, USA: A) a standard 0.32-cm-diameter $7 \times$ 19-strand cable with a cam-lock, B) a standard restraint but with a clear plastic tubing fitted over the cable on the capture loop, and C) a standard restraint but incorporating a twist-link chain into the capture loop.
Wildlife Services specialists set capture devices by first identifying an appropriate coyote capture site (based on landscape factors, spoor, and experience of the technician), then randomly selecting one of the 3 cable foot-restraints to use at that location. Whenever setting new equipment or moving to an existing site, WS specialists randomly selected a new cable restraint type. We checked all restraint devices daily and, thus, coyotes were held $\leq 24$ hours. When a coyote was captured, WS specialists euthanized it and collected the head and restrained leg and packed them on ice while in transport to a freezer. We marked each leg with the name of the collector, carcass identification number, cable restraint type, date, sex, and weight. We shipped samples to Utah State University, where a veterinary pathologist (who was blind to the device type) dissected and evaluated them. We compared injuries caused by the 3 cable foot-restraint types using injury scores per international standards for testing restraining traps (International Organization for Standardization [ISO] 1999). For comparison to previously evaluated capture devices, we also used scoring methods described by Onderka et al. (1990), and Phillips et al. (1996).

We used a factorial analysis of variance to compare main effects using factors of 1) sex of the coyote, 2) specialist, and 3) snare type to compare ISO injury scores for coyotes caught in each cable restraint type. When a main effect was significant, we used a Tukey's honestly significant difference (HSD) post hoc comparison to determine which factors were significantly different from one another. We used simple linear regression (Wessa Version 1.1.23-r3, www.wessa.net/slr.wasp, accessed 13 Oct 2008) to determine if there was a dependent relationship between the weight of the coyotes and injury scores within each cable foot-restraint type. For each statistical test, we used a critical alpha level of 0.05 .

\section{RESULTS}

We captured and examined 21, 17, and 14 coyotes in the standard, chain, and sleeved cables, respectively. We captured an additional 2 coyotes in the standard restraint, but did not examine them and instead assigned them an ISO score of 100 for death, per the scoring system. Numbers and types of injuries varied among cable foot-restraint types (Table 1). We found a difference in the mean injury scores among the 3 cable foot-restraint types (standard, $\bar{x}=37.9 \pm 6.3[\mathrm{SE}$ throughout]; chain, $\bar{x}=22.2 \pm 4.0$; sleeved, $\bar{x}=60.4$ $\left.\pm 14.8 ; F_{2,41}=4.63, P=0.015\right)$. When we used the Tukey's HSD test to compare one restraint to another, we found injury scores for coyotes captured in sleeved restraints were higher than those for coyotes captured in chain restraints $(P=$ 0.012). Comparisons between the standard restraint and the other 2 cable restraints were not significantly different.

Due to differences in the point values assigned to injuries and the types of injuries examined by the different authors' scoring systems, mean injury scores varied among the scoring systems (Table 2). We did not find a significant difference among the injury scores of the coyotes caught by the 5 different WS specialists (specialist $\mathrm{A}, \bar{x}=30.4 \pm 4.8$, $n=14$; specialist $\mathrm{B}, \bar{x}=55 \pm 40, n=2$; specialist $\mathrm{C}, \bar{x}=$ $46.8 \pm 11.3, n=17$; specialist $\mathrm{D}, \bar{x}=35.7 \pm 8.0, n=15$; 
Table 1. Reported injuries and associated International Standards Association (ISO 1999) injury scores from necropsies of legs and heads of coyotes captured in 3 types of cable foot-restraints in central California, USA, from May 2004 to July 2006.

\begin{tabular}{|c|c|c|c|c|c|c|c|c|c|c|}
\hline \multirow[b]{2}{*}{ Injury } & \multirow{2}{*}{$\begin{array}{l}\text { ISO injury } \\
\text { score }\end{array}$} & \multicolumn{3}{|c|}{ Standard $^{\mathrm{a}}(N=23)$} & \multicolumn{3}{|c|}{ Chain $^{\mathrm{b}}(N=17)$} & \multicolumn{3}{|c|}{ Sleeved $^{c}(N=14)$} \\
\hline & & No. & $\%$ & SE & No. & $\%$ & SE & No. & $\%$ & SE \\
\hline Edematous swelling or hemorrhage & 5 & 17 & 74 & 9 & 13 & 76 & 10 & 11 & 79 & 11 \\
\hline Cutaneous abrasion & 5 & 2 & 9 & 6 & 2 & 12 & 8 & 2 & 14 & 9 \\
\hline Cutaneous laceration & 10 & 11 & 48 & 10 & 10 & 59 & 12 & 8 & 57 & 13 \\
\hline $\begin{array}{l}\text { Minor (below carpus or tarsus) subcutaneous } \\
\text { soft-tissue maceration erosion }\end{array}$ & 10 & 9 & 39 & 11 & 10 & 59 & 12 & 4 & 29 & 12 \\
\hline $\begin{array}{l}\text { Major (above carpus or tarsus) subcutaneous } \\
\text { soft-tissue maceration erosion }\end{array}$ & 30 & 10 & 43 & 11 & 4 & 24 & 10 & 8 & 57 & 13 \\
\hline Minor periosteal abrasion & 10 & 2 & 9 & 6 & 0 & 0 & 0 & 1 & 7 & 7 \\
\hline Major periosteal abrasion & 30 & 3 & 13 & 7 & 1 & 6 & 6 & 1 & 7 & 7 \\
\hline Severence of minor tendon or ligament & 25 & 0 & 0 & 0 & 0 & 0 & 0 & 1 & 7 & 7 \\
\hline Severence of major tendon or ligament & 100 & 0 & 0 & 0 & 0 & 0 & 0 & 2 & 14 & 9 \\
\hline Simple fracture at or below the carpus or tarsus & 50 & 1 & 4 & 4 & 0 & 0 & 0 & 0 & 0 & 0 \\
\hline Permanent tooth fracture exposing pulp cavity, recent & 30 & 1 & 5 & 4 & 0 & 0 & 0 & 1 & 8 & 8 \\
\hline Death & 100 & 2 & 9 & 6 & 0 & 0 & 0 & 1 & 7 & 7 \\
\hline
\end{tabular}

${ }^{a}$ One head could not be examined because of a gunshot to the head.

${ }^{\mathrm{b}}$ Four heads could not be examined because of a gunshot to the head.

${ }^{c}$ Two heads could not be examined because of a gunshot to the head.

specialist $\left.\mathrm{E}, \bar{x}=10 \pm 0, n=1 ; F_{4,41}=0.65, P=0.63\right)$. Neither did we detect a statistical difference between injury scores of male and female coyotes $(\mathrm{M}, \bar{x}=39.6 \pm 6.2 ; \mathrm{F}, \bar{x}$ $\left.=35 \pm 8.8 ; F_{1,41}=1.10, P=0.30\right)$. We did not detect a dependent relationship between injury scores and weights for coyotes caught in the sleeved $\left(P=0.34, r^{2}=0.131\right)$ and standard cable restraints $\left(P=0.304, r^{2}=0.088\right)$, but we did detect a potential relationship between injury scores and weights for coyotes caught in the chained foot cable restraints $\left(P=0.046, r^{2}=0.315\right)$, with injury scores increasing with weight of the coyote.

\section{DISCUSSION}

Of the 3 devices we tested, the cable-sleeve had the highest mean injury score in all 3 injury-scoring systems that we used. One possible reason the sleeved cable caused more injury than standard or chained restraints is that the sleeve may have prevented the cable from tightening snugly on the coyote's foot, thus allowing movement of the leg against the lock. Such movement could be expected to cause lacerations, abrasions, and other injuries. The chain restraint exhibited the lowest mean injury scores for all 3 scoring systems. Potential reasons why the chain loop caused less injury are 1) the links within lengths of chain provided a greater, rounded, surface area than an equivalent length of cable and could distribute the pressure of the device's grip, and 2) the lengths of chain acted similar to teeth or buttons on some jawed-devices, which are thought to reduce movement of the device and thus reduce injury (Kuehn et al. 1986).

We had expected injury scores to increase with an increase in the weight of the coyote because of the increased force heavier coyotes could apply to the restraint on their leg. A positive relationship between weight and injury score was only detected in the chain restraint. However, this relationship was most likely due to a high injury score of the heaviest coyote caught in the chain foot-restraint device. Upon graphical examination of the data, it was clear that a single point leveraged the otherwise flat slope and caused a spurious relationship.

Comparisons of our results to other evaluations of foot restraints showed cable foot-restraint injury scores were similar to some other capture devices. Phillips et al. (1996) found 2 types of unpadded steel-jaw traps had higher mean injury scores than a padded steel-jaw trap, with scores of 103 , 79, and 29, respectively. Onderka et al. (1990) compared an unpadded steel-jaw trap, a padded steel-jaw trap, and 2 types of cable foot-restraint throwing devices with mean injury scores of $64.9,21.6,5.9$, and 59.4, respectively. The 3 restraints we tested all had lower injury scores than unpadded steel-jaw traps, but only the chain foot-restraint had slightly lower mean injury scores than the padded steel-jaw traps. Thus, current research suggests that unless a chain restraint is being used, a padded leg-hold trap may cause less injury to a captured coyote than cable restraints.

Table 2. Mean injury scores and standard error of coyotes caught in standard and modified cable foot-restraints in central California, USA, based on International Standards Association (ISO 1999), Onderka et al. (1990), and Phillips et al. (1996) injury-scoring systems.

\begin{tabular}{|c|c|c|c|c|c|c|}
\hline \multirow[b]{2}{*}{ Scoring system } & \multicolumn{2}{|c|}{ Standard cable foot-restraint $(N=21)^{\mathrm{a}}$} & \multicolumn{2}{|c|}{ Chain cable foot-restraint $(N=17)$} & \multicolumn{2}{|c|}{ Sleeved cable foot-restraint $(N=14)$} \\
\hline & $\bar{x}$ & $\mathrm{SE}$ & $\bar{x}$ & $\mathrm{SE}$ & $\bar{x}$ & SE \\
\hline ISO & 37.9 & 6.4 & 22.2 & 4.0 & 60.4 & 14.8 \\
\hline Onderka & 22.9 & 4.5 & 17.7 & 2 & 31.8 & 7.3 \\
\hline Phillips & 37.1 & 5.7 & 28.2 & 3.9 & 41.4 & 6.4 \\
\hline
\end{tabular}

${ }^{a} N=23$ for ISO injury score because of the inclusion of injury scores of 2 coyotes that died in the cable foot-restraint. 
For our statistical analysis, we used the ISO scoring system because it is an internationally accepted standard for scoring injuries of animals caught in restraining devices and it has the most comprehensive list of injuries and corresponding scores. However, injury scores are simply a way of comparing injuries caused by one capture device to those caused by another and cannot be translated to the amount of pain experienced by the animal caught in the capture device (Muñoz-Igualada et al. 2008). Furthermore, Engeman et al. (1997) suggested that injury scores are not appropriate for statistical analysis because assigned injury point values are arbitrary. Thus, the differences we detected between cable restraint types is indicative of differences in injury rates, but the actual difference in pain or welfare is at this point impossible to estimate.

Of the 3 injury-scoring systems we used to compare injuries related to cable foot-restraint devices, the ISO injury score was the only scoring system that showed a statistically significant difference among the 3 cable footrestraint types. Our results emphasize the importance of having a standardized injury-scoring system and examining as many injuries as possible. Several of the coyotes' injury scores when using the Onderka et al. (1990) and the Phillips et al. (1996) scoring systems were lower than the ISO scores because they did not account for injuries to the mouth, some injuries to the legs, or the death of coyotes while in the capture device. Despite possible problems with statistical inference when using injury scores, they are still a useful tool to allow comparisons between devices. In our study, all cases showed coyotes caught in sleeved cable foot-restraint devices had higher numerical, if not statistically significant, injury scores than coyotes caught in standard or chain cable restraints. All 3 scoring systems we used also showed that cable restraints with twisted link chain had the lowest injury scores, with mean injury scores similar to those of padded steel-jaw traps.

\section{Management Implications}

The ability to capture and handle animals is a very important aspect of wildlife management and wildlife research. Steeljaw traps have been made illegal in some areas and cable restraints are instead being used as a more socially acceptable option to capture coyotes. However, based on injury evaluations, our testing suggests padded steel-jaw traps may actually cause less injury than standard cable restraints. This study highlights the need to thoroughly test restraining devices and to use the best available scientific information when establishing guidelines for use. For example, wrapping a cable in a plastic sleeve may be thought to reduce injury to the captured animal because it would have a smoother contact surface with the animal's leg, but our data indicated that the sleeved cable was potentially more harmful.

\section{Acknowledgments}

We wish to thank the USDA WS California state program, especially specialists S. Galantine, D. Simms, P. Lacey, and R. Anderson for their work collecting samples and documenting the capture of coyotes for this study.

\section{LITERATURE CITED}

Bateman, J. A. 1971. Animal traps and trapping. Stackpole, Harrisburg, Pennsylvania, USA.

Cockrell, S. 1999. Crusader activists and the 1996 Colorado anti-trapping campaign. Wildlife Society Bulletin 27:65-74.

Engeman, R. M., H. W. Krupa, and J. Kern. 1997. On the use of injury scores for judging the acceptability of restraining traps. Journal of Wildlife Research 2:124-127.

Harris, S., C. Soulsbury, and G. Iossa. 2006. A scientific review on proposed humane trapping standards in Europe. The ISO Standards and the European proposal for a proposed Directive on humane trapping standards. University of Bristol, School of Biological Sciences, Bristol, United Kingdom.

International Organization for Standardization [ISO]. 1999. TC191. Animal (mammal) traps. Part 5: methods for testing restraining traps. International Standard ISO/DIS 10990-5. International Organization for Standardization, Geneva, Switzerland.

Kuehn, D. W., T. K. Fuller, L. D. Mech, W. J. Paul, S. H. Fritts, and W. E. Berg. 1986. Trap-related injuries to gray wolves in Minnesota. Journal of Wildlife Management 50:90-91.

Linhart, S. B., F. S. Blom, G. J. Dasch, R. M. Engeman, and G. H. Olsen. 1988. Field evaluation of padded jaw coyote traps: effectiveness and foot injury. Proceedings of the Vertebrate Pest Conference 13:226-229.

Muñoz-Igualada, J., J. A. Shivik, F. G. Dominguez, J. Lara, and L. M. Gonzalez. 2008. Evaluation of cage-traps and cable restraint devices to capture red fox in Spain. Journal of Wildlife Management 72:830-836.

Novak, M. 1981. The foot-snare and the leg-hold traps: a comparison. Proceedings of the Worldwide Furbearer Conference 3:1671-1685.

Olsen, G. H., S. B. Linhart, R. A. Holmes, G. J. Dasch, and C. B. Male. 1986. Injuries to coyotes caught in padded and unpadded steel foothold traps. Wildlife Society Bulletin 14:219-223.

Onderka, D. K., D. L. Skinner, and A. W. Todd. 1990. Injuries to coyotes and other species caused by four models of footholding devices. Wildlife Society Bulletin 18:175-182.

Orthmeyer, D. L., T. A. Cox, J. W. Turman, and J. R. Bennett. 2007. Operational challenges of solving urban coyote problems in southern California. Proceedings of the Wildlife Damage Management Conference 12:344-357.

Phillips, R. L., K. S. Gruver, and E. S. Williams. 1996. Leg injuries to coyotes captured in three types of foothold traps. Wildlife Society Bulletin 24:260-263.

Reiter, D. K., M. W. Brunson, and R. H. Schmidt. 1999. Public attitudes towards wildlife damage management and policy. Wildlife Society Bulletin 27:746-758.

Shivik, J. A., K. S. Gruver, and T. J. DeLiberto. 2000. Preliminary evaluation of new cable restraints to capture coyotes. Wildlife Society Bulletin 28:606-613.

Shivik, J. A., D. J. Martin, M. J. Pipas, J. W. Turman, and T. J. DeLiberto. 2005. Initial comparison: jaws, cables, and cage-traps to capture coyotes. Wildlife Society Bulletin 33:1375-1383.

United States Department of Agriculture Wildlife Services [USDA WS] 2006. Wildlife Services—California. <http://www.aphis.usda.gov/wildlife_damage/state_report_pdfs/FY_2006_State_Reports/016-California. pdf $>$. Accessed 14 Oct 2008.

Associate Editor: Nielsen. 